\title{
Growth failure and outcome in Rett syndrome
}

\author{
Specific growth references
}

Daniel Charles Tarquinio, DO

Kathleen J. Motil, MD, $\mathrm{PhD}$

Wei Hou, PhD

Hye-Seung Lee, PhD

Daniel G. Glaze, MD

Steven A. Skinner, MD Jeff L. Neul, MD, PhD

Fran Annese, LMSW

Lauren McNair, MS, CGC

Judy O. Barrish, BSN, RN

Suzanne P. Geerts, MS, RD

Jane B. Lane, BSN, RN

Alan K. Percy, MD

Correspondence \& reprint requests to Dr. Tarquinio: danieltarq@aol.com

Supplemental data at www.neurology.org

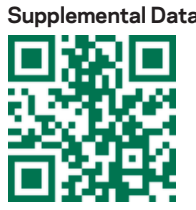

\section{ABSTRACT}

Objectives: Prominent growth failure typifies Rett syndrome (RTT). Our aims were to 1) develop RTT growth charts for clinical and research settings, 2) compare growth in children with RTT with that of unaffected children, and 3) compare growth patterns among RTT genotypes and phenotypes.

Methods: A cohort of the RTT Rare Diseases Clinical Research Network observational study participants was recruited, and cross-sectional and longitudinal growth data and comprehensive clinical information were collected. A reliability study confirmed interobserver consistency. Reference curves for height, weight, head circumference, and body mass index (BMI), generated using a semiparametric model with goodness-of-fit tests, were compared with normative values using Student's test adjusted for multiple comparisons. Genotype and phenotype subgroups were compared using analysis of variance and linear regression.

Results: Growth charts for classic and atypical RTT were created from 9,749 observations of 816 female participants. Mean growth in classic RTT decreased below that for the normative population at 1 month for head circumference, 6 months for weight, and 17 months for length. Mean BMI was similar in those with RTT and the normative population. Pubertal increases in height and weight were absent in classic RTT. Classic RTT was associated with more growth failure than atypical RTT. In classic RTT, poor growth was associated with worse development, higher disease severity, and certain MECP2 mutations (pre-C-terminal truncation, large deletion, T158M, R168X, R255X, and R270X).

Conclusions: RTT-specific growth references will allow effective screening for disease and treatment monitoring. Growth failure occurs less frequently in girls with RTT with better development, less morbidity typically associated with RTT, and late truncation mutations. Neurology ${ }^{\circledR}$ 2012;79:1653-1661

\section{GLOSSARY}

ANOVA $=$ analysis of variance; $\mathbf{B M I}=$ body mass index; $\mathbf{C S S}=$ Clinical Severity Score; EDF $=$ equivalent degrees of freedom; FDR = false discovery rate; FOC = fronto-occipital head circumference; $\mathbf{M B A}=$ Motor Behavioral Assessment; nonRTT = participants possessing MECP2 mutation but without Rett syndrome; RNHS = Rett Natural History Study; RTT = Rett syndrome.

Growth failure is a prominent feature in Rett syndrome (RTT); however, no RTT-specific growth charts exist. Many comorbid disorders have an impact on growth in RTT, such as oropharyngeal and gastrointestinal dysfunction, scoliosis, seizures, and osteopenia. The pattern of growth in female patients with RTT trends well below the lowest centile on standard growth references, ${ }^{1}$ which fail to differentiate a normal RTT growth pattern from one caused by malnutrition or illness.

Disease-specific standards screen for disease ${ }^{2-13}$ and measure the effect of therapeutic interventions designed to improve nutrition and neurologic function. ${ }^{14,15}$ With more than 200 mutation sites identified in the methyl-CpG-binding protein 2 gene (MECP2), the clinical

From the Miami Children's Hospital (D.C.T.), Miami, FL; Baylor College of Medicine (K.J.M., D.G.G., J.L.N., J.O.B.), Houston, TX; University of Florida (W.H.), Gainesville, FL; University of South Florida (H.-S.L.), Tampa, FL; Greenwood Genetic Center (S.A.S., F.A., L.M.), Greenwood, SC; and University of Alabama at Birmingham (S.G., J.L., A.K.P.).

Study funding: Supported by NIH U54 grants RR019478 (National Center for Research Resources) and HD061222 (National Institute of Child Health and Human Development [NICHD]), Intellectual and Developmental Disabilities Research Center grant HD38985 (NICHD), and funds from the International Rett Syndrome Foundation and Civitan International Research Center.

Go to Neurology.org for full disclosures. Disclosures deemed relevant by the authors, if any, are provided at the end of this article. 
severity in RTT varies widely. ${ }^{16}$ Associations exist among specific mutations and functional outcomes such as ambulation, hand use, and language. ${ }^{17}$ No study has generated accurate RTT growth references or adequately examined the associations between the degree of growth failure and genotype or clinical severity.

The aim of this study was to develop RTTspecific growth references for clinical and research use. The secondary objectives were to 1) compare the patterns of growth between patients with RTT and the normative population and 2) examine the effects of secular changes, disease severity, and MECP2 mutation on growth.

METHODS Participants and data collection. Participants with classic RTT and atypical RTT and MECP2-positive participants without clinical RTT (non-RTT) were recruited from 2006 to 2011 through the multicenter RTT Natural History Study (RNHS) at 1 of 7 sites and evaluated every 6-12 months as described previously. ${ }^{18}$ Diagnosis of classic and atypical RTT was based on consensus criteria ${ }^{19,20}$ and was confirmed by an RNHS neurologist or geneticist (D.G.G., J.L.N., A.K.P., S.A.S.). All participants had MECP2 testing; participants with clinical RTT were included despite absence of a mutation. Evaluation included fronto-occipital head circumference (FOC), weight, height, or length using standardized techniques, (appendix e-1 on the Neurolog $y^{\circledR}$ Web site at www.neurology.org) and 2 quantitative scales of developmental abilities and disease severity, the Motor Behavioral Assessment (MBA) and Clinical Severity Score (CSS) (appendix e-2). Interoperator and intraoperator reliability was excellent (within $3 \mathrm{~mm}$ or $0.3 \mathrm{~kg}$ ). To analyze secular trends, supplemental retrospective data were collected for participants seen by A.K.P. before the RNHS.

All female participants with classic and atypical RTT were included. Male participants $(n=20)$ were excluded, and nonRTT female participants $(\mathrm{n}=31)$ were excluded from growth chart construction because of the paucity of subjects but were retained for comparison of adult measurements. No participants were excluded based on premature birth or secondary medical conditions; however, data on comorbidities were collected. Corrected age was used for premature participants until 2 years of age. A recruitment goal of 750 participants ensured at least 30 observations at standard visit intervals up to 18 years. Although the age range of the charts extends to 18 years, data on individuals up to 25 years were included to attenuate the flaring "rightedge effect" of data truncation on statistical smoothing.

Standard protocol approvals, registrations, and patient consents. Institutional review board approval was obtained at each institution-based site; informed assent was obtained from participants' families. The RNHS is registered as clinical trial NCT00296764.

Statistical analysis. Data quality assurance. Data were screened using exploratory data analysis (individual scatterplots, boxplots, histograms, and quantile-quantile plots) to identify erroneous measurements and frequency at target ages. Erroneous measurements were investigated through source documentation, and unresolved errors were discarded. Measurements on scatter- plots were discarded if they differed from interpolated values by more than $2 \mathrm{~kg}$ for weight, $1 \mathrm{~cm}$ for FOC, or $2.5 \mathrm{~cm}$ for height; $1 \%$ were discarded.

Chart modeling. Charts for the 2nd, 9th, 25th, 50th, 75th, 91st, and 98th percentiles in classic and atypical RTT were created using combined cross-sectional and longitudinal data. Curves were modeled using LMS, ${ }^{21}$ a semiparametric technique that normalizes data using a power transformation $(\mathrm{L})$ and summarizes distribution based on median (M) and coefficient of variation (S). After transformation, the mean and median are equivalent. Values of $\mathrm{L}, \mathrm{M}$, and $\mathrm{S}$ are constrained to change smoothly with age through penalized maximum likelihood. The equivalent degrees of freedom (EDF) of curves for L, M, and S were manipulated based on goodness-of-fit testing, ${ }^{22}$ and EDF values were adjusted to achieve empirical validity and biological plausibility.

Chart comparisons. Charts were compared with normative references using multiple $t$ tests weekly for the first 3 months and monthly thereafter. Adjustment was made using the false discovery rate (FDR), the expected percentage of false predictions in a set of predictions. ${ }^{23}$ Because crossing 2 percentile lines (1.3 SDs) is commonly considered abnormal growth velocity, the percentage of participants who did so was calculated. British normative growth references were used because National Center for Health Statistics charts do not include data for age older than 3 years for FOC or younger than age 2 for body mass index (BMI). ${ }^{24}$

Charts were compared for RTT subgroups, including mild and severe groups based on bimodal distribution of CSS and MBA score. To study the effect of modern nutrition, secular changes were compared in those born before vs after the median year of birth (1997).

Genotype-phenotype and disease severity comparisons. Common mutation type clustering reduced 148 MECP2 mutations based on molecular similarities (common) into 8 common point, pre-C-terminal truncating, C-terminal truncating, large deletion, and other missense mutations (table 1). Measurements were compared among each category using analysis of variance (ANOVA) adjusted for multiple comparisons using the TukeyKramer test. Growth velocity (from baseline to 6 years), time to growth nadir, and measurements at key age ranges $(0-2,2-7$, $7-12,12-17$, and $>17$ years) were compared among different genotypes.

The associations of the severity of common RTT characteristics in childhood with adult measurements ( $\geq 18$ years old) were examined using linear regression. Characteristics included scoliosis severity (scoliosis), periodic breathing (hyperventilation), repetitive hand movements (stereotypies), seizure severity (seizure), ability to speak after regression (language) and communicate wants through nonverbal means (nonverbal), and age at which the following occurred or were acquired: hand use, ambulation, sitting unsupported (sitting), and regression of verbal and motor skills (regression). Puberty onset based on Tanner staging was compared with race-specific standards. ${ }^{25}$ Associations of age of pubertal onset with growth, RTT characteristics, and genotypes were examined. Patients were categorized based on proportion of FOC to somatic size. Associations of these proportions with diagnoses, secular trends, RTT characteristics, genotype, and pubertal onset were examined using ANOVA.

Analyses were performed using SAS version 9.1 (SAS Inc., Cary, NC), SPSS version 15.0 (SPSS Inc., Chicago, IL), and LMSChartmaker. ${ }^{26} \mathrm{~A}$ value of $p<0.05$ was considered significant for all tests, and FDR $<0.05$ was used to correct results for growth chart comparison. 


\begin{tabular}{|c|c|c|c|c|c|}
\hline \multicolumn{6}{|c|}{ MECP2 mutation categories and frequencies } \\
\hline \multirow[b]{2}{*}{ Classification } & \multirow[b]{2}{*}{ Mutation } & \multicolumn{2}{|c|}{$\begin{array}{l}\text { Classic RTT } \\
(\mathrm{n}=726)\end{array}$} & \multicolumn{2}{|c|}{$\begin{array}{l}\text { Atypical RTT } \\
(\mathrm{n}=90)\end{array}$} \\
\hline & & No. & $\%$ & No. & $\%$ \\
\hline \multirow[t]{5}{*}{ Type or location } & Truncating (pre-C-terminal) & 40 & 5.5 & 5 & 5.6 \\
\hline & C-terminal truncating & 51 & 7.0 & 12 & 13.3 \\
\hline & Large deletion & 57 & 7.9 & 3 & 3.3 \\
\hline & Other missense & 75 & 10.3 & 6 & 6.7 \\
\hline & Miscellaneous & 59 & 8.1 & 3 & 3.3 \\
\hline \multirow[t]{8}{*}{ Specific point } & T158M & 80 & 11.0 & 2 & 2.2 \\
\hline & $\mathrm{R} 255 \mathrm{X}$ & 70 & 9.6 & 5 & 5.6 \\
\hline & R168X & 71 & 9.8 & 2 & 2.2 \\
\hline & R306C & 47 & 6.5 & 7 & 7.8 \\
\hline & R294X & 41 & 5.7 & 4 & 4.5 \\
\hline & R270X & 42 & 5.8 & 2 & 2.2 \\
\hline & $\mathrm{R} 133 \mathrm{C}$ & 31 & 4.3 & 10 & 11.1 \\
\hline & R106W & 25 & 3.4 & 1 & 1.1 \\
\hline None & No mutation & 37 & 5.1 & 28 & 31.1 \\
\hline
\end{tabular}

RESULTS Of 878 female participants, 8 RNHS and 54 supplemental participants were excluded because of unconfirmed diagnoses. The remaining participants, 726 with classic RTT and 90 with atypical RTT, were followed up to 3.25 years (mean 1.5 years).

Demographics. Participants were mostly Caucasian and non-Hispanic (table 2). Birth year ranged from 1945 to 2008. Nearly all lived at home, and none born after 1997 lived in a group home or institution. Two-thirds were diagnosed before age 4 years, and half were enrolled by age 10 .

Mutation frequencies. Among 816 participants, 751 (92\%) had mutations in MECP2, including 689 with classic RTT (95\%) and 62 with atypical RTT (69\%). The 8 common point mutations made up $56 \%$ of classic RTT and 37\% of atypical RTT mutations (table 1).

Measurements. Overall, 9,749 observations were recorded, averaging 12 per individual: 9,240 weight, 6,992 height, 6,178 FOC, and 6,937 BMI; the majority $(90.6 \%)$ were for participants with classic RTT. The number of observations decreased with age but remained greater than 40 per year in classic RTT (table e-1). Height measurements included $44 \%$ recumbent, $50 \%$ standing, and $6 \%$ calculated from segmental measurements. After 3 years of age, the majority were measured standing. Measurement type did not affect average height before 5.5 years, beyond which average height or length was shorter in participants measured recumbent. After 2.5 years, CSS was higher for participants measured recumbent.

\section{Table 2 Demographic characteristics of the cohort $(n=816)^{a}$}

\begin{tabular}{|c|c|c|}
\hline Characteristic & No. & $\begin{array}{l}\% \text { all with } \\
\text { data }\end{array}$ \\
\hline \multicolumn{3}{|l|}{ Race } \\
\hline Caucasian & 589 & 88 \\
\hline African American & 39 & 6 \\
\hline Asian & 35 & 5 \\
\hline American Indian & 7 & 1 \\
\hline \multicolumn{3}{|l|}{ Ethnicity } \\
\hline Hispanic & 106 & 15 \\
\hline Non-Hispanic & 589 & 85 \\
\hline \multicolumn{3}{|l|}{ Residence } \\
\hline Home & 618 & 98 \\
\hline Group home & 9 & 1 \\
\hline Institution & 3 & 1 \\
\hline \multicolumn{3}{|l|}{ Gestational age } \\
\hline Gestational age range $27-36$ wk & 50 & 6 \\
\hline \multicolumn{3}{|l|}{ Year of birth } \\
\hline Born before January 1, 1997 & 365 & 46 \\
\hline \multicolumn{3}{|l|}{ Age at enrollment } \\
\hline$<10 y$ & 345 & 58 \\
\hline$>10 y$ & 252 & 42 \\
\hline \multicolumn{3}{|l|}{ Age of diagnosis } \\
\hline$<1 y$ & 6 & 1 \\
\hline $1-<2 y$ & 105 & 18 \\
\hline $2-<3 y$ & 169 & 29 \\
\hline $3-<4 y$ & 96 & 17 \\
\hline $4-<5 y$ & 58 & 10 \\
\hline $5-<10 y$ & 93 & 16 \\
\hline $10-20 y$ & 37 & 7 \\
\hline$>20 y$ & 13 & 2 \\
\hline
\end{tabular}

a Data could not be collected on all participants for all demographic categories.

Summary statistics. Birth. Mean birth measurements in participants with both classic and atypical RTT were similar to those in the normative population (data not shown).

Adulthood. Adult RTT measurements were homogeneously distributed from normal (obese in the cases of weight and BMI) to extremely low (table 3). Average adult age was 25.4 years. Final adult height, weight, BMI, and FOC for participants with classic and atypical RTT were lower than those for nonRTT participants $(p<0.001)$; however, no difference existed between those with classic and atypical RTT.

Growth references. The LMS method generated classic RTT charts with empirical data evenly distributed at younger ages and moderately dense at older ages. At $\pm 3 \mathrm{SD}$ the charts tended to overestimate weight 


\begin{tabular}{|c|c|c|c|c|c|c|c|c|}
\hline Table 3 & \multicolumn{8}{|c|}{$\begin{array}{l}\text { Average and extreme weight, height, FOC, and BMI values in adult women ( } \geq 18 \text { years) with } \\
\text { Rett syndrome }\end{array}$} \\
\hline $\begin{array}{l}\text { Rett } \\
\text { diagnosis }\end{array}$ & Measurement & $\begin{array}{l}\text { No. of } \\
\text { observations }\end{array}$ & Mean & $\begin{array}{l}\text { SD } \\
\text { score }\end{array}$ & Minimum & $\begin{array}{l}\text { SD } \\
\text { score }\end{array}$ & Maximum & $\begin{array}{l}\text { SD } \\
\text { score }\end{array}$ \\
\hline \multirow[t]{4}{*}{ Classic } & Weight, kg & 220 & 40.3 & -3.5 & 21.2 & -9.4 & 94.7 & 3.0 \\
\hline & Height, $\mathrm{cm}$ & 205 & 141.7 & -3.7 & 114.7 & -8.1 & 170.0 & 1.0 \\
\hline & $\mathrm{FOC}, \mathrm{cm}$ & 211 & 51.2 & -3.1 & 46.5 & -6.5 & 57.1 & 1.2 \\
\hline & $\mathrm{BMI}, \mathrm{kg} / \mathrm{m}^{2}$ & 204 & 20.0 & -1.3 & 10.6 & -9.5 & 36.0 & 3.0 \\
\hline \multirow[t]{4}{*}{ Atypical } & Weight, kg & 26 & 47.0 & -1.5 & 27.6 & -6.4 & 87.7 & 2.6 \\
\hline & Height, cm & 24 & 145.9 & -2.9 & 103.6 & -9.9 & 161.9 & -0.3 \\
\hline & $\mathrm{FOC}, \mathrm{cm}$ & 21 & 51.5 & -2.9 & 47.0 & -6.1 & 55.0 & -0.4 \\
\hline & $\mathrm{BMI}, \mathrm{kg} / \mathrm{m}^{2}$ & 24 & 21.9 & 0.3 & 12.6 & -5.7 & 37.1 & 3.2 \\
\hline
\end{tabular}

Abbreviations: $\mathrm{BMI}=$ body mass index $\mathrm{FOC}=$ fronto-occipital head circumference.

by $0.2-2 \mathrm{~kg}$ near 5 years and height by $0.2-1.8 \mathrm{~cm}$ near 10 years. Empirical fit for FOC was consistent throughout.

Patterns of growth in classic RTT. Weight. The mean weight trajectory for classic RTT diverged below the normative pattern at age 6 months (figure 1). Mean weight was lower than the normative at 13 months $(p=0.04, \mathrm{FDR}=0.05)$. By age 12.5 years, mean weight was equal to the normative second percentile. Weight distribution was wider than that in unaffected children, and between 7 and 12 years, $6.4 \%$ were above the 98 th percentile. By 18 years, $71 \%$ of participants were below the second percentile on the normative reference. When participants were examined individually, $80 \%$ fell below the second percentile for weight at some point during development; only $51 \%$ of participants declined in weight velocity $>1.3 \mathrm{SD}$.

Height. Mean RTT height fell below the normative mean by 17 months $(p=0.02, \mathrm{FDR}=0.03)$ (figure 1). By age 12 years, mean height was $-2 \mathrm{SD}$. The distribution of height was also wide; between 12 and 17 years, $7.9 \%$ of participants were taller than the 98th percentile. By 18 years, $84.5 \%$ of adults were below the second percentile for height. Individual height velocity fell $>1.3 \mathrm{SD}$ in $41 \%$ of participants, and $87.5 \%$ were below the second percentile for height at some point.

FOC. Mean FOC for RTT fell below the normative mean by 1 month $(p<0.0001, \mathrm{FDR}<0.0001)$ (figure 2). By 2 years, mean FOC was -2 SD; no individual had an FOC above the 98th percentile thereafter. At 18 years, $81 \%$ were below the second percentile. Individual FOC velocity fell $>1.3 \mathrm{SD}$ in $44 \%$, and $86 \%$ had a minimum FOC below the second percentile at some point.

$B M I$. The mean BMI trajectory for children with RTT fell slightly below that for normal children at 4-5 months, but mean RTT BMI was similar to the normative mean after 9 months (figure 2). At 18 years, the average BMI was 20 , compared with 21 for normal women. The distribution was wide with $36 \%$ below the normative second percentile and 19\% above the 98th percentile at some point in development, typically between 12 and 17 years. Despite normal average BMI, growth failure was evident in BMI velocity, which fell $>1.3$ SD in $57 \%$ of participants.

Growth patterns. When proportions of measurements were compared, 5 distinct patterns emerged: 1) severe somatic growth deficit with microcephaly $(\mathrm{n}=239) ; 2)$ preserved, normal somatic growth with microcephaly $(\mathrm{n}=219)$; 3) moderate somatic growth deficit with microcephaly $(\mathrm{n}=140) ; 4)$ moderate somatic growth deficit with preserved, normal head size $(\mathrm{n}=21)$; and 5$)$ normal growth $(\mathrm{n}=$ 104).

Classic vs atypical RTT. No differences in average measurements were found between participants with classic and atypical RTT. Growth patterns were different $(p<0.01)$, with a higher proportion of participants with atypical RTT exhibiting either preserved somatic growth with microcephaly or normal growth (patterns 2 and 5) (figure e-1A).

Based on secular trends. Mean standardized weight was lower in participants born before 1997 ( $\mathrm{M}=$ -1.86), compared with those born during or after $1997(\mathrm{M}=-1.42, p=0.05)$. A higher proportion of participants born during or after 1997 exhibited growth pattern 2 , preserved somatic growth with microcephaly $(p<0.001)$ (figure e-1B).

Rett syndrome characteristics. Functional limitations, including overall severity, hand use, ambulation, nonverbal communication, scoliosis, seizures, stereotypies, hyperventilation, sitting, and regression were associated with lower adult measurements (table e-2), but verbal language was not. Growth proportions were associated with overall disease severity, 


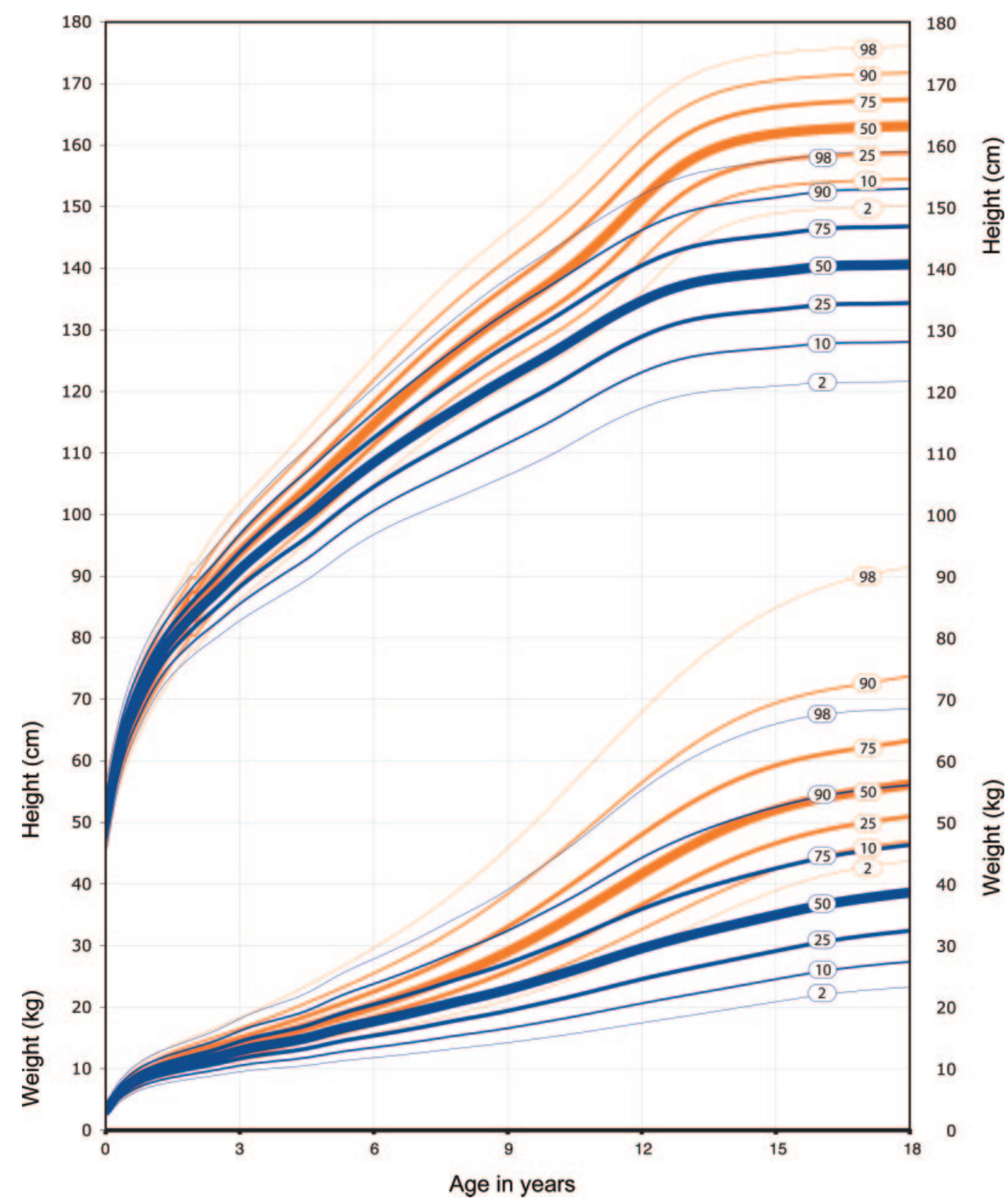

Height in Rett syndrome falls below the normative population at 21 months, and weight is lower at 13 months. Pubertal growth spurt is attenuated.

hand use, ambulation, scoliosis, seizures, sitting ( $p<$ $0.001)$ but not with language, stereotypies, hyperventilation, or regression. Preserved somatic growth, with or without microcephaly, was associated with better outcome (patterns 2 and 5) (figure e-1, C-H).

Genotype and growth. Two- to 7-year age range and mutation $(n=494)$. Weight was higher in participants with C-terminal truncation than in those with preC-terminal truncation, large deletion, no mutation, T158M, R168X, and R255X ( $p<0.001)$. BMI was also higher in those with late truncation than in those with either early truncation or large deletion $(p=$
0.001). Head circumference was higher in those with the R294X point mutation than in those with $\mathrm{R} 255 \mathrm{X}$ and R270X point mutations ( $p=0.001$ ).

Seven- to 12-year age range and mutation $(n=272)$. Head circumference was smaller in participants with pre-C-terminal truncation than in the other missense and no mutation groups, and smaller in those with large deletion than in those with no mutation $(p<0.05)$.

Adult $(n=169)$. No significant difference in final average adult measurements existed among mutation types. 
Figure 2 Head circumference and body mass index (BMI) in unaffected children (orange) and children with classic Rett syndrome (blue)

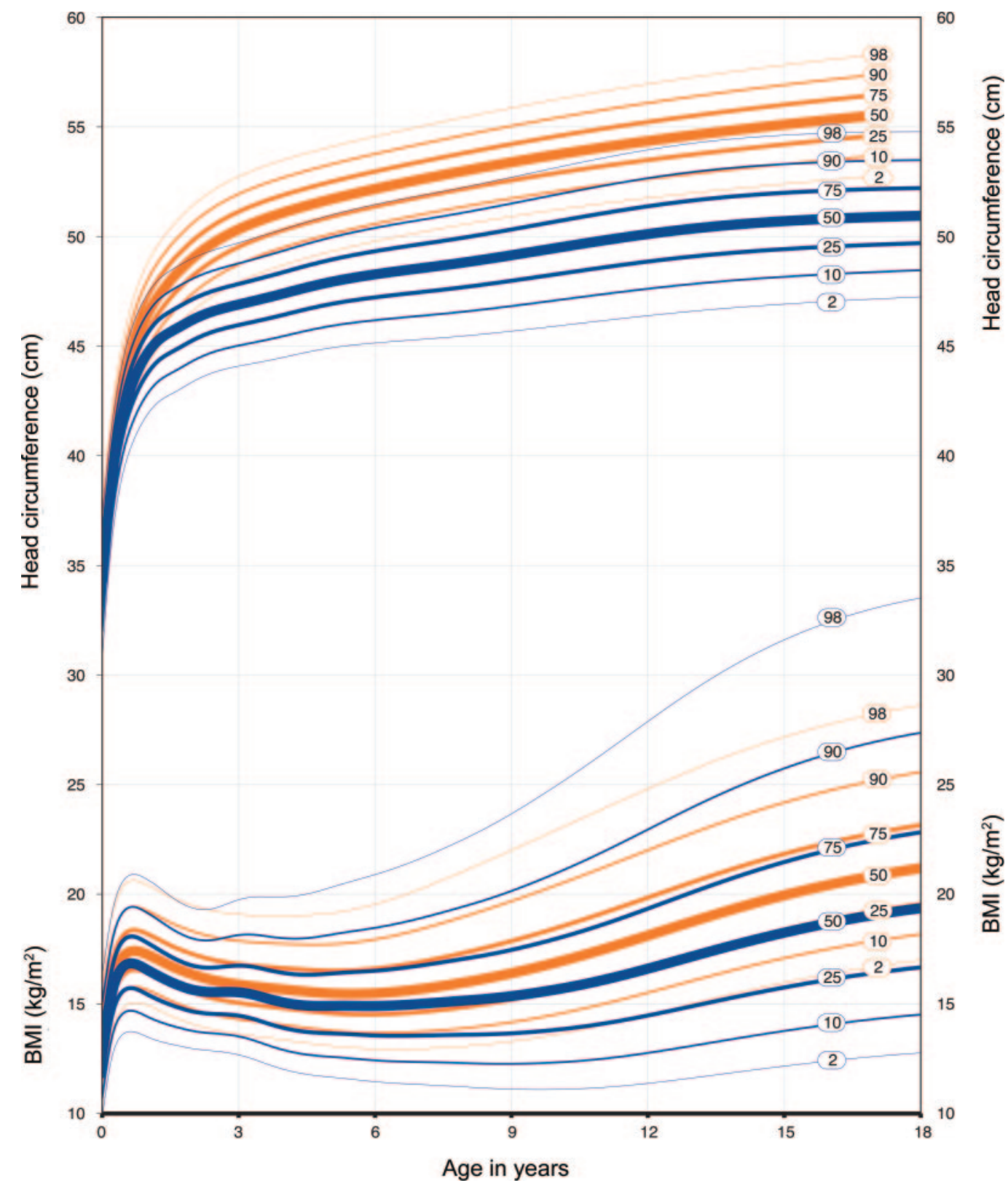

Head circumference in Rett syndrome falls below the normative population at 1 month of age. Average BMI is similar to normative population, but distribution is wider.

Growth velocity and mutation. The decline in standardized weight from baseline to 6 years was lower in participants with $\mathrm{C}$-terminal truncation than in those with pre-C-terminal truncation, large deletion, other missense, T158M, R255X, and R270X $(p<0.001)$. Average weight velocity was lower for those with R270X than for those with R306C and R133C ( $p<0.001)$. BMI velocity was higher in those with $\mathrm{C}$-terminal truncation than in those with large deletion, other missense, R294X, and $\mathrm{R} 270 \mathrm{X}(p=0.001)$. Head circumference velocity was lower in those with pre-C-terminal truncation than in the C-terminal truncation group $(p<$ 0.05).

Age at minimum SD score and mutation. Participants with pre-C-terminal truncation and large deletion reached their minimum standardized weight at an earlier age than those with $\mathrm{C}$-terminal truncation $(p<0.05)$. Likewise, those with pre-C-terminal truncation reached their minimum BMI before those with C-terminal truncation $(p<0.05)$. The pre-Cterminal truncation group reached minimum FOC before the other missense group, and those with R270X reached their FOC nadir before those with 
R294X and R133C ( $p<0.05)$. None of these associations was influenced by age of the participants at the final measurement.

Puberty and growth in classic RTT. Age of pubertal onset $(\mathrm{n}=66)$ ranged from 5.1 to 16.6 years and was associated with final height, weight, and BMI $(p<$ 0.001 ) but not with any measures of disease severity or specific MECP2 mutations. Normal pubertal onset adjusted for race occurred in $85 \%$, with precocious puberty in $12 \%$ and late-onset puberty in $3 \%$. Patterns of growth varied with age of pubertal onset $(p<0.001)$. Average age of pubertal onset was $8.8 \pm 0.9$ years in participants with normal growth (pattern 5), $9.3 \pm 1.7$ years in those with microcephaly and preserved somatic growth (pattern 2), $10.2 \pm$ 0.8 years in those with microcephaly and mild somatic growth failure (pattern 3), and $11.5 \pm 1.7$ years in those with microcephaly and global somatic growth failure (pattern 1) (figure e-1I).

DISCUSSION Growth studies in RTT have been limited to small populations $s^{1,27-29}$ or specific anthropometric measurements, ${ }^{30,31}$ and most were performed before MECP2 mutations were discovered or used statistical methods insufficient for calculating $z$ scores. This study demonstrates that the patterns of growth in RTT are different from those in unaffected individuals. Functional gross motor, fine motor, and nonverbal language deficits, as well as the presence of seizures, scoliosis, and RTT behaviors earlier in life are associated with severity of growth failure in late childhood and adolescence. Research on acquired microcephaly suggests that sparing of somatic growth confers a better developmental outcome. ${ }^{32} \mathrm{We}$ found that despite persistent microcephaly, preserved somatic growth occurs in $45 \%$ of girls with RTT and is associated with better development and lower seizure, scoliosis, and RTT behavior burden, contradicting dogma that "proportional" microcephaly conveys a protective effect. The resting metabolic rate is higher in patients with RTT than in those with other developmental disabilities, ${ }^{33}$ and intensive nutritional therapy improves growth outcomes. These findings suggest both that growth is an important outcome for clinical trials and that improved nutrition could moderate the association between growth and development. ${ }^{34}$

No study has adequately examined BMI in RTT. One assessed BMI in large age clusters that precluded analysis of BMI velocity. ${ }^{35}$ Despite height and weight failure, mean BMI in classic RTT is similar to that of unaffected, healthy females. Because BMI distribution in RTT is wide, standard BMI values overestimate low BMI. Conversely, decreasing BMI velocity was a sensitive marker for weight failure when abso- lute values were normal. Notably, the normal pubertal increase in height or weight velocity was absent in RTT. Although height in normative references is invariably positively skewed, height in adults with RTT was negatively skewed, suggesting that few women with RTT are tall, whereas many are extremely short.

Mutation in MECP2 was associated with growth velocity, the crucial prerequisite of growth failure. Growth failure was more evident in those with mutations associated with greater clinical severity such as pre-C-terminal truncation and R270X than in mutations associated with a milder burden such as R306C, R133C, and C-terminal truncation. ${ }^{17}$ Conditional references based on genotype could aid in studying the factors contributing to growth failure in RTT and response to treatment.

Concern exists that disease-specific charts based on biased methodology or insubstantial data will become standards for a disorder. ${ }^{36}$ However, most individuals with RTT after age 7-8 years have measurements less than $-3 \mathrm{SD}$ compared with those for unaffected individuals. ${ }^{30,35}$ Statistical comparisons beyond $-3 \mathrm{SD}$ contain insufficient empirical data and are imprecise. ${ }^{37}$ This study addressed methodologic concerns by recruiting 7\% of the RTT population in the United States, ranging in disease severity and coming from many racial, ethnic, and geographical backgrounds, through the International Rett Syndrome Foundation. Although not designed for longitudinal data, LMS produces precise curves ${ }^{38}$ and was selected from among 30 methods by the World Health Organization. ${ }^{39}$

The benefit of the World Health Organization prescriptive standards based on normal, healthy, breastfed international populations remains unclear. ${ }^{40}$ Alternately, empirical data restricted to certain outcomes regarded as favorable could represent the standard for growth in the disorder. One limitation of this study is that quantitative measures of therapeutic or nutritional intervention were not incorporated. Gastrostomy tube supplementation affects growth, and other interventions such as physical therapy may as well. Several potential contributors to growth failure, such as nutrition, seizure disorder, anxiety, constipation, gastroesophageal reflux, and orthopedic issues, can be modified. The RNHS study is currently collecting information on these aspects of health care that will be included in subsequent analyses designed to identify prescriptive targets for normal growth.

Our growth charts will allow researchers to more precisely examine the effects of novel RTT treatments. Moreover, clinicians will be able to assess medical health and the effect of interventions. As 
definitions of "healthy" individuals with RTT emerge from the natural history study, prescriptive standards of growth will provide objective data about how individual children with RTT should be growing. Comparison of aggressive and standard treatment of variables influencing growth could lend further insight into the interplay between nutrition, growth, and health in individuals with RTT.

\section{AUTHOR CONTRIBUTIONS}

Daniel C. Tarquinio: study conduct, data collection, manuscript preparation. Kathleen J. Motil: study conceptualization, study conduct, data collection, manuscript review. Wei Hou: statistical analysis, manuscript review. Hye-Seung Lee: study conduct, data collation and statistical analysis, manuscript review. Daniel G. Glaze: study conduct, data collection, manuscript review. Steven A. Skinner: study conduct, data collection, manuscript review. Jeffrey L. Neul: study conduct, data collection, manuscript review. Fran Annese: study conduct, data collection, manuscript review. Lauren McNair: study conduct, data collection, manuscript review. Judy O. Barrish: study conduct, data collection, manuscript review. Suzanne Geerts: study conduct, data collection, manuscript review. Jane B. Lane: study conceptualization, study conduct, data collection, manuscript preparation. Alan K. Percy: Study conceptualization, study conduct, data collection, manuscript preparation.

\section{ACKNOWLEDGMENT}

The authors thank Professor Tim Cole for his advice on growth reference modeling methodology.

\section{DISCLOSURE}

D. Tarquinio reports no disclosures. K. Motil serves on the International Rett Syndrome Foundation (IRSF) Scientific Review Committee and is funded by the NIH. W. Hou and H.-S. Lee report no disclosures. D. Glaze serves on the Scientific Advisory Board of IRSF and the Executive Committee of RettSearch and is funded by the NIH. S. Skinner serves on the Scientific Advisory Board of IRSF and is funded by the NIH. J. Neu serves on the Scientific Advisory Board of IRSF and the Executive Committee of RettSearch and is funded by the NIH. F. Annese is funded by the NIH. L. McNair is funded by the NIH. J. Barrish serves on the IRSF Professional Advisory Board and is funded by the NIH. S. Geerts is funded by the NIH. J. Lane is a paid consultant of the IRSF regarding clinical matters related to Rett syndrome and is funded by the NIH. A. Percy serves on the Scientific Advisory Board of IRSF is the principal investigator for the Rare Diseases Clinical Research Center grant for Angelman, Rett, and Prader-Willi syndrome grant (NICHD); is funded by the NIH; and receives administrative support from the UAB Civitan International Research Center. Go to Neurology.org for full disclosures.

Received December 8, 2011. Accepted in final form May 29, 2012.

\section{REFERENCES}

1. Schultz RJ, Glaze DG, Motil KJ, et al. The pattern of growth failure in Rett syndrome. Am J Dis Child 1993; 147:633-637.

2. Brooks J, Day S, Shavelle R, Strauss D. Low weight, morbidity, and mortality in children with cerebral palsy: new clinical growth charts. Pediatrics 2011;128:e299-e307.

3. Martin ND, Smith WR, Cole TJ, Preece MA. New height, weight and head circumference charts for British children with Williams syndrome. Arch Dis Child 2007;92:598601.

4. Myrelid A, Gustafsson J, Ollars B, Anneren G. Growth charts for Down's syndrome from birth to 18 years of age. Arch Dis Child 2002;87:97-103.
5. Marinescu RC, Mainardi PC, Collins MR, et al. Growth charts for cri-du-chat syndrome: an international collaborative study. Am J Med Genet 2000;94:153-162.

6. Clementi M, Milani S, Mammi I, Boni S, Monciotti C, Tenconi R. Neurofibromatosis type 1 growth charts. Am J Med Genet 1999;87:317-323.

7. Wollmann HA, Schultz U, Grauer ML, Ranke MB. Reference values for height and weight in Prader-Willi syndrome based on 315 patients. Eur J Pediatr 1998;157: 634-642.

8. Rongen-Westerlaken C, Corel L, van den Broeck J, et al. Reference values for height, height velocity and weight in Turner's syndrome: Swedish Study Group for GH treatment. Acta Paediatr 1997;86:937-942.

9. Witt DR, Keena BA, Hall JG, Allanson JE. Growth curves for height in Noonan syndrome. Clin Genet 1986;30: 150-153.

10. Horton WA, Rotter JI, Rimoin DL, Scott CI, Hall JG. Standard growth curves for achondroplasia. J Pediatr 1978;93:435-438.

11. Frisch H, Waldhauser F, Lebl J, et al. Congenital adrenal hyperplasia: lessons from a multinational study. Horm Res 2002;57(suppl 2):95-101.

12. Erkula G, Jones KB, Sponseller PD, Dietz HC, Pyeritz RE. Growth and maturation in Marfan syndrome. Am J Med Genet 2002;109:100-115.

13. Stevens CA, Hennekam RC, Blackburn BL. Growth in the Rubinstein-Taybi syndrome. Am J Med Genet Suppl 1990;6:51-55.

14. Appan S, Laurent S, Chapman M, Hindmarsh PC, Brook CG. Growth and growth hormone therapy in hypochondroplasia. Acta Paediatr Scand 1990;79:796-803.

15. Ranke MB, Blum WF, Haug F, et al. Growth hormone, somatomedin levels and growth regulation in Turner's syndrome. Acta Endocrinol 1987;116:305-313.

16. Amir RE, Van den Veyver IB, Wan M, Tran CQ, Francke $\mathrm{U}$, Zoghbi HY. Rett syndrome is caused by mutations in $\mathrm{X}$-linked MECP2, encoding methyl-CpG-binding protein 2. Nat Genet 1999;23:185-188.

17. Neul JL, Fang P, Barrish J, et al. Specific mutations in methyl-CpG-binding protein 2 confer different severity in Rett syndrome. Neurology 2008;70:1313-1321.

18. Glaze DG, Percy AK, Skinner S, et al. Epilepsy and the natural history of Rett syndrome. Neurology 2010;74: 909-912.

19. Hagberg B, Hanefeld F, Percy A, Skjeldal O. An update on clinically applicable diagnostic criteria in Rett syndrome: comments to Rett Syndrome Clinical Criteria Consensus Panel Satellite to European Paediatric Neurology Society Meeting, Baden Baden, Germany, 11 September 2001. Eur J Paediatr Neurol 2002;6:293-297.

20. Neul JL, Kaufmann WE, Glaze DG, et al. Rett syndrome: revised diagnostic criteria and nomenclature. Ann Neurol 2010;68:944-950.

21. Cole TJ, Green PJ. Smoothing reference centile curves: the LMS method and penalized likelihood. Stat Med 1992;11: 1305-1319.

22. Pan $\mathrm{H}$, Cole TJ. A comparison of goodness of fit tests for age-related reference ranges. Stat Med 2004;23:17491765.

23. Benjamini $Y$, Hochberg Y. Controlling the false discovery rate: a practical and powerful approach to multiple testing. J R Stat Soc Ser B 1995;57:289-300. 
24. Cole TJ, Freeman JV, Preece MA. British 1990 growth reference centiles for weight, height, body mass index and head circumference fitted by maximum penalized likelihood. Stat Med 1998;17:407-429.

25. Herman-Giddens ME, Slora EJ, Wasserman RC, et al. Secondary sexual characteristics and menses in young girls seen in office practice: a study from the Pediatric Research in Office Settings network. Pediatrics 1997;99:505-512.

26. Cole T, Pan H. LMSChartmaker, a program to construct growth references using the LMS method, version 2.54 [online]. Available at: http://www.healthforallchildren.com/index.php/ shop/product/Software/12KgQZiZ8fPdmMDS/0. Accessed September 4, 2012.

27. Reilly S, Cass H. Growth and nutrition in Rett syndrome. Disabil Rehabil 2001;23:118-128.

28. Thommessen M, Kase BF, Heiberg A. Growth and nutrition in 10 girls with Rett syndrome. Acta Paediatr 1992; 81:686-690.

29. Holm VA. Physical growth and development in patients with Rett syndrome. Am J Med Genet Suppl 1986;1:119-126.

30. Hagberg G, Stenbom Y, Engerstrom IW. Head growth in Rett syndrome. Brain Dev 2001;23(suppl 1):S227-S229.

31. Schultz R, Glaze D, Motil K, Hebert D, Percy A. Hand and foot growth failure in Rett syndrome. J Child Neurol 1998; 13:71-74.

32. Rosman NP, Tarquinio DC, Datseris M, et al. Postnatalonset microcephaly: pathogenesis, patterns of growth, and prediction of outcome. Pediatrics 2011;127:665-671.
33. Platte P, Jaschke H, Herbert C, Korenke GC. Increased resting metabolic rate in girls with Rett syndrome compared to girls with developmental disabilities. Neuropediatrics 2011;42:179-182.

34. Motil KJ, Morrissey M, Caeg E, Barrish JO, Glaze DG. Gastrostomy placement improves height and weight gain in girls with Rett syndrome. J Pediatr Gastroenterol Nutr 2009;49:237-242.

35. Oddy WH, Webb KG, Baikie G, et al. Feeding experiences and growth status in a Rett syndrome population. J Pediatr Gastroenterol Nutr 2007;45:582-590.

36. Ranke MB. Disease-specific standards in congenital syndromes. Horm Res 1996;45(suppl 2):35-41.

37. Cole T. Do growth charts centiles need a facelift? BMJ 1994;308:641-642.

38. Wade AM, Ades AE. Incorporating correlations between measurements into the estimation of age-related reference ranges. Stat Med 1998;17:1989-2002.

39. Borghi E, de Onis M, Garza C, et al. Construction of the World Health Organization child growth standards: selection of methods for attained growth curves. Stat Med 2006;25:247-265.

40. Mei Z, Ogden CL, Flegal KM, Grummer-Strawn LM. Comparison of the prevalence of shortness, underweight, and overweight among US children aged 0 to 59 months by using the CDC 2000 and the WHO 2006 growth charts. J Pediatr 2008;153:622-628.

\section{Practicing Neurologists: Take Advantage of These CMS Incentive Programs}

\section{Medicare Electronic Health Records (EHR) Incentive Program}

The Medicare EHR Incentive Program provides incentive payments to eligible professionals, eligible hospitals, and critical access hospitals as they adopt, implement, upgrade or demonstrate meaningful use of certified EHR technology. Through successful reporting over a five-year period, neurologists are eligible for up to $\$ 44,000$ through the Medicare incentive program. To earn the maximum incentive amount, eligible professionals must begin demonstrating meaningful use by October 3, 2012. Learn more at www.aan.com/go/practice/pay/ehr.

\section{Medicare Electronic Prescribing (eRx) Incentive Program}

The Medicare eRx Incentive Program provides eligible professionals who are successful electronic prescribers a $1 \%$ incentive for meeting reporting requirements during the 2012 calendar year. To be eligible, physicians must have adopted a "qualified" eRx system in order to be able to report the eRx measure. This program has also begun assessing payment adjustments for eligible professionals who have not yet begun participation in the program. Learn more at www.aan.com/go/practice/pay/eRx.

\section{Physician Quality Reporting System (PQRS)}

The Physician Quality Reporting System provides an incentive payment for eligible professionals who satisfactorily report data on quality measures for covered professional services furnished to Medicare beneficiaries. Eligible professionals who report successfully in the 2012 PQRS Incentive Program are eligible to receive a $0.5 \%$ bonus payment on their total estimated Medicare Part B Physician Fee Schedule allowed charges for covered professional services. Learn more at www.aan.com/go/practice/pay/pqrs. 